\title{
Analysis of Comfort Parameters in Special Purpose Vehicles from Technological Development Point of View
}

\author{
Milan STANKOVIĆ, Aleksandar MIĆOVIĆ, Aleksandar SEDMAK, Vladimir POPOVIĆ
}

\begin{abstract}
The analysis of comfort parameters in the crew cabin space of two variants of the special purpose off-road vehicle is presented, taking technological development aspects into account. Tests of noise, vibration and heating - cooling efficiency have been performed in realistic operating conditions, during the intensive driving on three selected test tracks, in order to ensure the repeatability of the obtained results. Measuring of noise and vibration levels at the drivers, co-drivers and crew members' seats were performed at strictly defined vehicle speed. Heating efficiency tests for the cabin have been performed in laboratory conditions, inside a cold chamber with the constant temperature of $\left(-16^{\circ} \mathrm{C}\right)$, whereas cooling efficiency tests were conducted in the hot chamber at the temperature of $\left(+40^{\circ} \mathrm{C}\right)$. The results of these tests enable the selection of a more comfortable variant of vehicle, wherein the one with less seats for passengers in the cabin which, in addition to more comfort also has the advantage of greater storage space, and from the application flexibility standpoint, which is offered by the possibility of transporting more passengers and less load, such vehicles offer better environment control from within the vehicle.
\end{abstract}

Keywords: noise; thermal comfort; vehicle comfort; vibration

\section{INTRODUCTION}

Yugoslav Zastava Factory (hereinafter referred to as Zastava) started a technical cooperation with Italian automotive producer FIAT in 1954. The assembly of the first vehicles was done after standard 2, which implied that the complete off-road vehicle model FIAT AR51/55 was mounted at 2-3 working tables. Zastava's technology level was above Yugoslav average but was handicapped because of poor tools and delivery by national companies. The technological level of the most important production equipment factors in Zastava was quite satisfactory and competitive with the technological equipment level of the European manufacturers. The educational level of the staff, especially those at university level, was satisfactory, as well as technical skills of employees, but proper respect of procedures was not always observed [1].

The development of the automotive industry and the sudden increase of competition in the market dictate increasing obligations of manufacturers to fulfil complex user and legal demands, in terms of economy, comfort, safety, as well as environmental protection. All of the above encouraged the development of new systems in motor vehicles, which influenced the car manufacturers and the automotive industry to devote attention to technical innovations in order to meet the demands related to higher comfort of the cabin, vehicle safety and fuel consumption reduction [2].

The comfort of the drivers and crew members during their time spent in the vehicle is inexctricably connected to the active and passive vehicle safety systems. Active safety assumes that the vehicle and its active elements do not pose the risk that could lead to a traffic accident, and that they do not affect the driver's physical and mental state in a way that could reduce his ability to properly and timely react to complex trafic scenarios. The vehicle construction and its equipment need to, as passive elements, prevent and mitigate the consequences (injuries) in the case of an accident. Thus, vehicle elements that affect its safety in traffic can be classified in three groups [3]:

- Active vehicle safety elements,

- Passive vehicle safety elements and

- Catalytic vehicle safety elements.
Active vehicle safety elements, whose breaking or failure can lead to trafic accidents include the devices which affect the stability and maneuverability, devices used for maneuvering and braking, (efficiency, stability, reliability), pneumatics, gear transmission, driver's field of vision and potential presence of "blind spots", lights, the visibility of the vehicle by other participants in traffic (color, signaling system), comfort etc.

Passive vehicle safety elements, which do not affect the frequency of accidents, but improve the protection against them, i.e. they reduce the effects of the forces acting on the passengers, include the car body (crumpled zones), safety belts, airbags, head rests, tank properties and electrical instalations, external and internal equipment (shape of the passenger space - cabin, adjustable plastic inner devices, filleted decorations), the position of the engine block and aggregate, bumpers, the extension of the front part between the cabin and the engine (deformation space) etc.

Catalytic vehicle safety elements include presence of exhaust gases, vibrations, heating and cooling within the vehicle cabin. In addition to affecting vehicle safety, catalytic parameters include ergonomic properties of the vehicle. Ergonomic properties include the possibility of adjusting the vehicle interior to the characteristics of each individual driver and crew members. Vehicle structure should be adapted to the majority of users and enable individual adjustments, taking into account its dimensions, for the purpose of: better visibility from the vehicle, higher comfort, comfortable sitting, easier driving, better access and use of controls and devices, better sound and heat isolation, reduced vibration effect and driver's fatigue.

Off-road vehicles include special purpose enginedriven vehicles, which are used both on regular roads, under normal weather conditions and on difficult terrain and under complex weather conditions. For these reasons, especially due to their use in complex driving and weather conditions, it is necessary that the manufacturers of such vehicles devote special attention to testing and adjusting the models to comply with the existing standards during the design and development of test models [4], in order to 
ensure that the user's health is protected. A specific problem related to off-road vehicles originates from the fact that they have long work life (over 50 years), which may cause them to fall behind the automotive industry standards which are constantly being changed. For the purpose of this study, the test results for two prototypes of off-road vehicles manufactured at the Zastava Trucks factory in Kragujevac (hereinafter referred to as Pt-1 and Pt-2) were used. The test models are shown in Fig. 1 and Fig. 2, whereas Tab. 1 shows the general technical information about these off-road vehicles.

Table 1 Technical information about "model PT1" and "model PT2"

\begin{tabular}{|l|c|c|}
\hline General information & model PT1 & model PT2 \\
\hline Type & HKWM 40.12 & HKRKWM 40.12 \\
\hline Drive & \multicolumn{2}{|c|}{$4 \times 4$} \\
\hline Load bearing capacity & \multicolumn{2}{|c|}{$1,4 \mathrm{t}$} \\
\hline Pneumatics & \multicolumn{2}{|c|}{$255 / 100 \mathrm{R} 16$} \\
\hline Engine & IVEKO SOFIM 8140.43S \\
\hline Nominal engine power & \multicolumn{2}{|c|}{$92 \mathrm{~kW}(125 \mathrm{KS})$} \\
\hline Mass & \multicolumn{2}{|c|}{$3070 \mathrm{~kg}$} \\
\hline Height & $2520 \mathrm{~mm}$ & $2350 \mathrm{~mm}$ \\
\hline Width & $2220 \mathrm{~mm}$ & $2170 \mathrm{~mm}$ \\
\hline Length & $4948 \mathrm{~mm}$ & $4915 \mathrm{~mm}$ \\
\hline
\end{tabular}

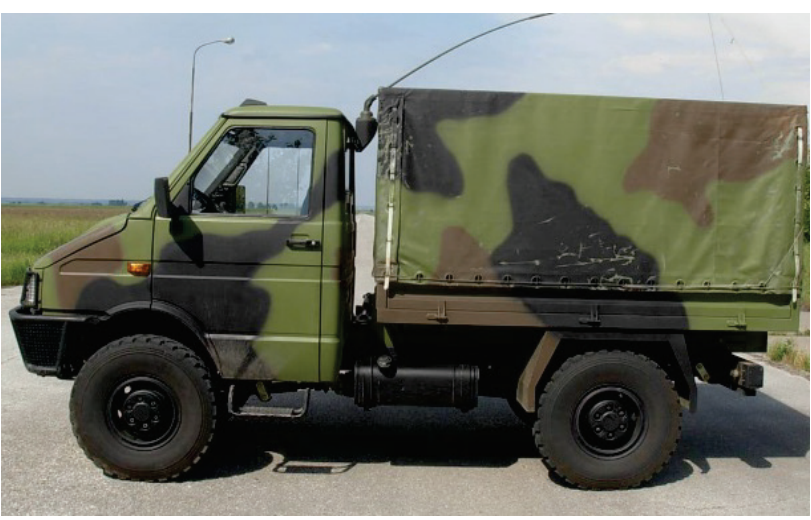

Figure 1 "Model PT1", 4×4, 1,4 t

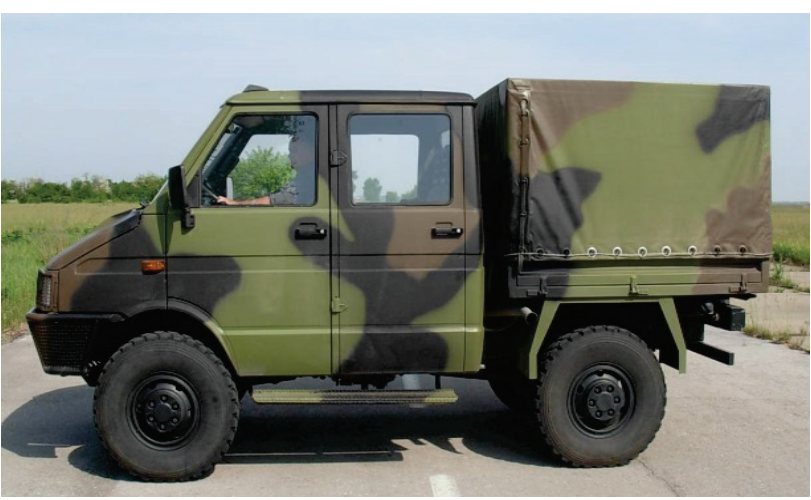

Figure 2 "Model PT2", 4×4, 1.4 t

\section{INTERNAL NOISE IN THE VEHICLE CABIN}

Noise which occurs within the motor vehicle cabin is complex and caused by multiple sources. In addition to its unwanted effects on driver's focus and fatigue, unlike in the case of commerical vehicles, during noise test in army vehicles, special attention needs to be devoted to its interference with crew member communication, as well as their perception and reaction time to external factors.
Taking into account that the main purpose of these vehicles is transportation in off-road conditions, comfort tests within the vehicle cabin in terms of noise was performed while driving on a macadam road, i.e. an intersected slope, in addition to driving along an asphalt road according to ISO 5128 standard [5]. Thus, the scope of the test was expanded, in accordance with the Noise exposure directive, 2003/10/ES. Special attention was given to the measuring under off-road conditions (due to the vehicle's purpose and the frequency of use in such conditions), at constant speeds which corresponded to the previously established average vehicle speed in such terrain $(30-40 \mathrm{~km} / \mathrm{h})$ [6].

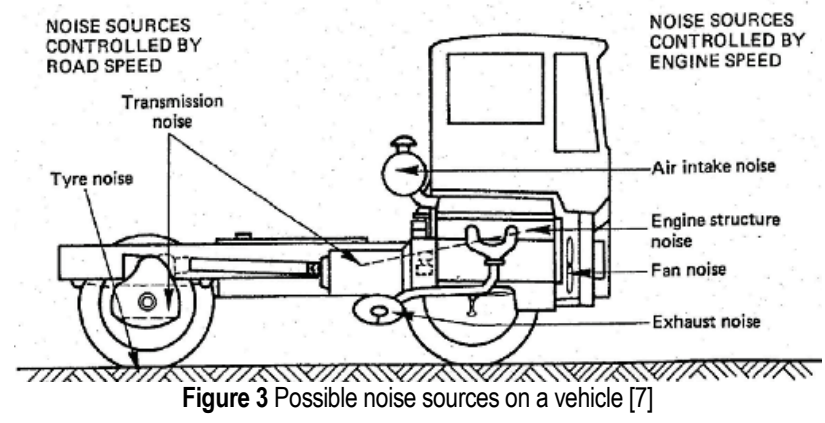

First part of testing, involving an asphalt road, involved the measuring of the vehicle's maximum speed, so that the speed modes at which internal noise is measured can be determined during the second stage (stable spped mode and full acceleration mode). Measuring was performed using a non-contact device for dynamic vehicle properties, Corrsys Datron, with an optical uniaxial sensor Corevit L-350 Aqua.

Noise measuring was performed simultaneously at the driver's and crew member's seats while driving on asphalt, with vehicle cabin windows closed. In such conditions, the vehicle can be considered as a workspace used for performing a set of functions by the crew members. In the national legislation of the Republic of Serbia, allowed noise levels are regulated by the Rulebook of measures and normatives for occupational protection from noise in workspaces [8].

\section{VIBRATION MEASURING}

The car body itself is one of the most significant sources of vibration in cars. Its structure represents an oscillating continuum and is affected, apart from bumps, by the engine, its elastic supports connecting it to the engine space, and also by oscillations due to transmission, the exhaust system, support and driving system and the brake system. In other words, all systems and elements connected to the body. Vibration parameters influence characteristics of vehicles which are relevant for vehicle comfort [9].

Exposure to vibration can affect humans in different ways, from regular disturbance to reduction of work efficiency, health risks and even health damage. Vibrations can be classified as:

- Vibrations affecting the arms and hands,

- Vibrations affecting the whole body - full body vibrations on mobile machines and equipment such as 
motor vehicles, construction machinery, graders, loaders on wheels and tracks, tractors, forklifts working on uneven terrain, army vehicles.

Harmful effects of vibration on humans manifest in form of headaches, increased irritability, frequent changes in blood pressure, stomach contractions etc. Vibrations transferred directly to the hands cause muscle pain, tendon inflammations, damages to the soft tissues and bones in hands and changes in the wrists. Autors of a research of the influence of vehicle vibration parameters, introduced presumption that vibration parameters depend on service conditions affecting dynamic characteristics of a vehicle, and they concluded that road microprofile and vehicle speed are relevant for comfort [10].

For the purpose of determining the quantitative oscillatory load to which the driver and the crew are subjected, it is of great importance to choose adequate seats. Seat vibrations that occur during driving (forced oscillation) are transferred to the whole body of a passenger along the three axes. Measuring of axial acceleration, along with other representative parameters, and the evaluation of results were done in accordance with ISO 2631 (comfort) standard [11], as well as the European directive EC/44/02 (Health damage criteria). Standard ISO 2631 enables the evaluation based on three different aspects: preserving of human health, preserving of ability (fatigue limit) and preserving of comfort. The analysis was performed with the frequency range of $0.5-80 \mathrm{~Hz}$. However, since the exposure risk was not the same for all frequencies, frequency ponderation had to be used in order to represent the risk in an objective way. This resulted in the pondered acceleration drop relative to the increase in frequency. Two different frequency ponderations were used for full body vibrations. The first ponderation (Wd) was used for two lateral axes, $x$ and $y$, whereas the second (Wk) was used for the vertical $z$-axis. From the aspect of human health preservation, the values of measured acceleration for the lateral axes, $x$ and $y$, was multiplied by a factor of 1.4 (it is assumed that the vibrations in these directions are aroud $40 \%$ more damaging to the human spinal column compared to the longitudinal direction), whereas in the case of the vertical, $\mathrm{z}$-axis, the ponderation factor was 1.0. From the aspect of comfort preservation, ponderation factors for the seater position were 1.0 .

The Directive on vibrations allows for the evaluation of the level of vibrations using two methods:

- determining the level of daily exposure $\mathrm{A}(8)-$ equivalent continuous acceleration calculated for 8hour work time. Value $\mathrm{A}(8)$ is based on root-mean square averaging of the acceleration signal $\left(\mathrm{m} / \mathrm{s}^{2}\right)$;

- value of vibration dose (VDV), which represents a cumulative dose and it is obtained as the fourth root of effective value (root-mean-quad) of the acceleration signal $(\mathrm{m} / \mathrm{s} 1,75)$.

The value of daily exposure $A(8)$ as the end value of measurement is compared with the limit values which are set by the European Directive "Vibrations" (2002/44/EC) [12]: action threshold at which it should take action $\mathrm{A}(8)$ $=0,5 \mathrm{~m} / \mathrm{s}^{2}$, and maximum threshold $\mathrm{A}(8)=1,15 \mathrm{~m} / \mathrm{s}^{2}$. The measuring of vibrations in three axes was performed by the use of a three-axis accelerometer fitted into the seat adapter as an integral part of the set of specific-purpose measuring instrument Maestro $01 \mathrm{~dB}$ produced by Metravib, which was manufactured according to ISO 8041 standard requirements [13].

\section{MEASURING OF HEATING AND COOLING EFFICIENCY IN THE VEHICLE CABIN}

Comfort conditions typically include the air state in the cabin, expressed via projected internal temperature. Comfortable conditions within the cabin and the vehicle are determined by the air state, and the main factors which affect this state are: the temperature, humidity, streaming speed and air purity.

Another important parameter influencing the comfort within the cabin is the heating and cooling efficiency. Human body temperature is around $37{ }^{\circ} \mathrm{C}$. Constant maintaining of body temperature is achieved by the body emiting the heat it produces to the surroundings, i.e. by keeping the body from excess heat emission. Insufficient excessive heat emission results in an uncomfortable feeling, reducing the mental and physical ability. In order to create optimal working and living conditions in a workspace (an enclosed space), the air temperature should be between $16{ }^{\circ} \mathrm{C}$ and $22^{\circ} \mathrm{C}$. All of the above emphasizes the great importance of adequate design of an efficient heating and cooling system for vehicle cabins, which are observed as the workspace in this case.

Car manufacturers put considerable effort into providing vehicles with excellent systems, because the thermal climate in the passenger area has a strong influence on health, safety, comfort, and performance of drivers and passengers. Poor climate conditions may affect the driver performance, decreasing the ability to concentrate and the arousal level.

Due to the specificness of the test procedure, and the involvement of laboratory spaces used as cold and hot chambers, the tests were adapted to the conditions, methods and criteria defined by the ISO 7730 standard for Moderate thermal environments - Determination of the PMV and PPD indices and specification of the conditions for thermal comfort. This standard describes the PMV (Predicted Mean Vote) and PPD (Predicted Percentage Dissatisfied) indices and specifies acceptable conditions for thermal comfort. The PMV predicts the mean value of the votes of a large group of people on the ISO thermal sensation scale $(+3=$ hot; $+2=$ warm; $+1=$ slightly warm; $0=$ neutral; $-1=$ slightly cool; -2 $=$ cool $;-3=$ cold $)$. The PPD predicts the percentage of a large group of people likely to feel 'too warm' or 'too cool'. A draft rating index is provided in the standard as an equation involving air temperature, air velocity and turbulence intensity. It is applicable to mainly sedentary people wearing light clothing with a whole-body thermal sensation close to neutral. Recommended thermal comfort requirements are provided in Annex D of the standard (informative - not a formal part of the standard). This includes optimum operative temperature; vertical air temperature gradient; mean air velocity; floor temperature; and relative humidity [14].

\section{COMFORT PARAMETERS TEST PROCEDURE}

As mentioned in the previous text, testing of comfort elements in the cabin was performed on three types of test tracks (intersected slope, flat macadam and asphat). For the purpose of comparing the results, measuring was 
performed on absolutely identical sections of test tracks, under strictly defined vehicle speeds. In the case of dirt roads, depending on the vehicle category, maximum alowed sppeds range from 30 to $40 \mathrm{~km} / \mathrm{h}$. Vehicle speeds in off-road conditions are determined based on the previous extensive experience during the use of the same test tracks. The main parameters used for determining of sppeds was the safe vehicle motion along the track, the evaluation of test drivers, as well as the mean speed achieved during the whole test cycle [7]. Based on the regulations from ISO 5128 standard, the speed was defined for driving along the ashpalt road, for measuring of the internal noise in the vehicle cabin. Vibrations in the driver's seat were also measured at constant speeds. One of the problems that was encountered during the testing were the different time intervals of seasons during which the tests were performed, wherein there was always a tendency to keep the test track dry and safe for driving, as well as to ensure that the ambiental conditions (outside temperature, wind speed) do not affect the measured results. Testing of the vibrations effect was performed with selected testers, weighing up to $100 \mathrm{~kg}$. Due to a wide range of data obtained by this measuring, the tables shown here only contain the results for speeds of $30 \mathrm{~km} / \mathrm{h}$ and $40 \mathrm{~km} / \mathrm{h}$ in off-road conditions, and for speeds of 60 and $80 \mathrm{~km} / \mathrm{h}$ for asphalt roads.

Comfort tests within the vehicle cabin in terms of noise levels were performed during driving on an asphalt road according to ISO 5128 standard, the macadam track and the intersected slope, in accordance with the noise exposure directive 2003/10ES. The measurements were carried out with the vibroacoustic measuring system NetdB12 (01dB Metravib) and with three microphones fitted to adapters level with the driver's and passengers' heads. "Fast" time dynamic characteristic and "A" frequency weighting of sound pressure were chosen. During all measurements the weather conditions were satisfactory (humidity, temperature and wind), as well as ambient noise (considerably lower than $10 \mathrm{~dB}$ when compared to the cabin), so that subsequent corrections of the results were not necessary. A driver, co-driver and one passenger were present in the vehicle during the measurement. Measuring was performed at the test tracks and a part of the Belgrade - Šid highway. Measured maximum speeds in certain gears corresponded to the speeds declared by the manufacturer.

Measuring of noise during driving on asphalt, within the cabin with windows closed, was performed in two cycles:
- At stable speeds within the range of $40 \%$ max. speed to $80 \%$ max speed. $(60 \mathrm{~km} / \mathrm{h}$ to $80 \mathrm{~km} / \mathrm{h}$, in fourth gear),

- During acceleration tests (from $50 \mathrm{~km} / \mathrm{h}$ to $100 \mathrm{~km} / \mathrm{h}$, also in fourth gear).

\section{ANALYSIS OF RESULTS OF OFF-ROAD VEHICLE "MODEL PT1"}

\subsection{Results of Internal Noise Measuring, "Model PT1"}

By analyzing all of the measured noise levels, it can be seen that the mean noise value in the cabin of the "model PT1" during driving on the slope was 70-71 dB(A), whereas for the macadam it surpassed $77 \mathrm{~dB}(\mathrm{~A})$ at the driver seat, and in the case of asphalt roads, it averaged 73-75 $\mathrm{dB}(\mathrm{A})$ at stable speeds. During the acceleration tests, the equivalent noise level reached a value of $79 \mathrm{~dB}(\mathrm{~A})$, Tab. 2 .

Table 2 Total Noise measuring results for the cabin of "model PT1"

\begin{tabular}{|c|c|c|c|}
\hline \multirow{2}{*}{ model PT1 } & Noise level, $L_{\mathrm{eq}}(\mathrm{dB}(\mathrm{A}))$ \\
\cline { 3 - 4 }$(\mathrm{km} / \mathrm{h})$ & Gear & Driver & Co-driver \\
\hline 60 & IV & 74.4 & 72.5 \\
\hline 80 & IV & 75.3 & 75.5 \\
\hline \multicolumn{4}{|c|}{ Stable speed at intersected slope heathland } \\
\hline 30 & III & 71.1 & 71.5 \\
\hline 40 & III & 69.7 & 72.6 \\
\hline \multicolumn{5}{|c|}{ Stable speeds at flat macadam gravel } \\
\hline 30 & III & 77.7 & 75.9 \\
\hline 40 & III & 76.6 & 74.5 \\
\hline \multicolumn{5}{|c|}{ Acceleration, fourth gear on asphalt } \\
\hline $50-100$ & IV & 78.4 & 78.1 \\
\hline
\end{tabular}

It is obvious that the measured noise levels in the cabin of "model PT1" were below the threshold prescribed by the Directive 2003/10/ES (80 dB(A) - lower action value, in which cases the employer is required to provide the worker with protective equipment). Equivalent noise level in the vehicle cabin was lower than the value prescribed by the Rulebook of measures and normatives for occupational protection from noise in workspaces (Official Gazette of SFRJ, no. 21/92), which is $80 \mathrm{~dB}(\mathrm{~A})$ in case of transport vehicles.

\subsection{Vibrations Test Results for "Model PT1"}

The results of the vibration test for "model PT1" are given in Tab. 3, for all three types of tracks.

Table 3 Total results of comfort measurements from the aspect of oscillatory comfort of an off-road vehicle, "model PT1"

\begin{tabular}{|c|c|c|c|c|}
\hline Track & Measuring location & $\begin{array}{r}\text { Speed } \\
(\mathrm{km} / \mathrm{h})\end{array}$ & $\begin{array}{l}\text { Equivalne triaxial accelerations vs. } \\
\text { Comfort } a_{v}\left(\mathrm{~m} / \mathrm{s}^{2}\right)\end{array}$ & Comfort rating \\
\hline \multirow{4}{*}{ Asphalt } & \multirow{2}{*}{ Driver } & 60 & 0.45 & Slightly uncomfortable \\
\hline & & 80 & 0.78 & Mostly uncomfortable \\
\hline & \multirow{2}{*}{ Co-driver } & 60 & 0.70 & Mostly uncomfortable \\
\hline & & 80 & 0.78 & Mostly uncomfortable \\
\hline \multirow{4}{*}{$\begin{array}{c}\text { Slope } \\
\text { heathland }\end{array}$} & \multirow{2}{*}{ Driver } & 30 & 1.57 & Very uncomfortable \\
\hline & & 40 & 1.76 & Very uncomfortable \\
\hline & \multirow[b]{2}{*}{ Co-driver } & 30 & 1.70 & Very uncomfortable \\
\hline & & 40 & 1.80 & Very uncomfortable \\
\hline \multirow{4}{*}{$\begin{array}{l}\text { Flat macadam } \\
\text { gravel }\end{array}$} & \multirow[b]{2}{*}{ Driver } & 30 & 1.62 & Very uncomfortable \\
\hline & & 40 & 1.56 & Very uncomfortable \\
\hline & \multirow{2}{*}{ Co-driver } & 30 & 1.88 & Very uncomfortable \\
\hline & & 40 & 2.10 & Extremely uncomfortable \\
\hline
\end{tabular}


Based on the oscillatory comfort criteria, the driver's seat is considered to be very uncomfortable when driving along the slope and macadam. Discomfort is even more prominent at the co-driver's seat, wherein at speeds of 40 $\mathrm{km} / \mathrm{h}$, macadam, it turns into extremely uncomfortable. Driving on asphalt is generaly uncomfortable - Tab. 4 for both driver and co-driver. Taking into account the health risk criteria, it can be seen from these results that driving these off-road vehicles should be limited by speed, depending on the type of track.

\subsection{Heating Efficiency of the "Model PT1" Cabin}

Determininig of the micro-climate properties of the workspace was only performed for the off-road vehicle "model PT1". Tests were performed in a cold chamber for a duration of 24 hours. Heating efficiency was tested at the environment temperature of $\left(-16{ }^{\circ} \mathrm{C}\right)$. Tests were performed according to appropriate standards for testing of heat related comfort of off-road vehicle workspaces. A total of 10 temperature sensors connected to the measuring device Fluke 2166 AK were placed inside the vehicle cabin.

An integrated sensor MM0023, connected to a THERMAL COMFORT METER TYPE 1212 device, manufactured by Brüel \& Kjaer, was placed in the center of the cabin. Both instruments were used for measuring during the test. Integrated sensor MM0023 was placed at a height of $0.6 \mathrm{~m}$ from the floor, at an angle of $30^{\circ}$ relative to the vertical axis. Temperature measuring sensors were placed at the heights of the head, chest and feet of the driver and the other crew members, in their seated positions.

After starting the engine in the cold chamber, the oil temperature in the engine crankcase was measured. After half an hour from starting, while the engine was running at $1500 \mathrm{rpm}$, oil temperature in the crankcase reached $32^{\circ} \mathrm{C}$. At this moment, the testing of the heat related comfort of the cabin was initiated. Table 4 shows the values measured by the digital thermometer Fluke 2166 AK, whereas Table 5 shows the results obtained by measuring using the integrated sensor MM0023 device.

Table 4 Temperature measured by Fluke 2166 AK

\begin{tabular}{c|c|c|c|c|c|c|c|c|c|c|}
\multicolumn{10}{c|}{} & \multicolumn{10}{c|}{ Table 4 Temperature measured by Fluke 2166 AK } \\
\cline { 2 - 12 } \multicolumn{1}{c|}{} & \multicolumn{10}{c|}{ MEASURING POINTS $\left({ }^{\circ} \mathrm{C}\right)$} \\
\cline { 2 - 11 } & 1 & 2 & 3 & 4 & 5 & 6 & 7 & 8 & 9 & 10 \\
\hline Start (min) & -14 & +32 & -16 & -15 & -14 & -14 & -13 & -15 & -14 & -15 \\
\hline 5 & -11 & 32 & -16 & -5 & 7 & 5 & -1 & 8 & 15 & -13 \\
\hline 10 & -8 & 33 & 6 & -1 & 11 & 7 & 2 & 11 & 15 & -15 \\
\hline 15 & -6 & 36 & 10 & 1 & 13 & 9 & 4 & 13 & 15 & -17 \\
\hline 20 & -2 & 36 & 13 & 5 & 16 & 13 & 7 & 17 & 14 & -19 \\
\hline 25 & -1 & 37 & 16 & 7 & 18 & 14 & 9 & 19 & 14 & -15 \\
\hline 30 & 0 & 38 & 18 & 8 & 18 & 15 & 10 & 19 & 15 & -18 \\
\hline 35 & 1 & 37 & 19 & 9 & 20 & 17 & 11 & 20 & 15 & -18 \\
\hline 40 & 3 & 37 & 20 & 11 & 21 & 18 & 12 & 21 & 15 & -16 \\
\hline 45 & 4 & 40 & 20 & 12 & 22 & 19 & 14 & 23 & 15 & -15 \\
\hline 50 & 4 & 41 & 22 & 12 & 23 & 21 & 14 & 23 & 15 & -15 \\
\hline 55 & 5 & 40 & 23 & 13 & 23 & 22 & 15 & 24 & 14 & -16 \\
\hline 60 & 6 & 41 & 23 & 14 & 24 & 22 & 15 & 25 & 14 & -18 \\
\hline
\end{tabular}

Table 5 Heat related comfort measured using the sensor MM0023

\begin{tabular}{|c|c|c|c|c|c|c|}
\cline { 2 - 7 } \multicolumn{1}{c|}{} & Oper.temp & Comp.temp & Equi.temp & Dif.temp & PMV & PPD \\
\hline Start (min) & -17.9 & 24.9 & -24.6 & 49.5 & -7.3 & 21 \\
\hline 5 & -4.4 & 24.9 & -24.6 & 49.5 & -5.4 & 21 \\
\hline 10 & -2.1 & 24.9 & -23.5 & 49.2 & -2.2 & 18 \\
\hline 15 & -0.3 & 24.9 & -23.3 & 42.7 & -2.1 & 18 \\
\hline 20 & 1.3 & 24.9 & -23.2 & 32.5 & -1.4 & 14 \\
\hline 25 & 15.1 & 24.9 & -8.2 & 27 & 0.81 & 12 \\
\hline 30 & 8 & 24.9 & -2.1 & 36.7 & 0.66 & 12 \\
\hline 35 & 17.1 & 24.9 & 1.4 & 23.2 & 0.57 & 12 \\
\hline 40 & 19.1 & 24.9 & 6.2 & 18.7 & 0.52 & 10 \\
\hline 45 & 10.2 & 24.9 & 8.6 & 32.1 & 0.38 & 7.2 \\
\hline 50 & 10.6 & 24.9 & 7.5 & 31.4 & 0.31 & 6.8 \\
\hline 55 & 11.2 & 24.9 & 7.1 & 24.6 & 0.39 & 6.5 \\
\hline 60 & 11.6 & 24.9 & 7 & 30.2 & 0.43 & 7.3 \\
\hline
\end{tabular}

\section{TEST RESULTS FOR OFF-ROAD VEHICLE "MODEL} PT2"

\subsection{Internal Noise Test Results, "Model PT2"}

During the analysis of the internal noise in the cabin, the focus was on tests performed on asphalt, different vehicle exploitation modes. Off-road vehicle "model PT2" actually represents a modified prototype "model PT1", obtained by extending the vehicle cabin and adding another row of seats behind the driver. After noise measuring tests have been performed, same noise levels were determined at the driver's and co-driver's seats, hence the measuring was performed using a dual channel microphone set, simultaneously for the first and second rows. Taking into account that, in addition to speed, gear is a very important factor, measuring was performed in a somewhat wider range than that required by standards ISO 5128 and the internal standard SORS 0031 which is used by the Technical test center, for the purpose of internal noise testing of vehicles. 
Microphone was placed at a height of $0,65 \pm 0,05 \mathrm{~m}$ above the seat and at a distance of $0,2 \pm 0,02 \mathrm{~m}$ to the right of the longitudinal symmetry axis of the seat. The standard requires that the microphone is placed horizontally, facing the driving direction, while ensuring it is at least $0.15 \mathrm{~m}$ from walls or upholstered parts.

Table 6 Total results for noise measuring in the cabin of vehicle "model PT2"

\begin{tabular}{|c|c|c|c|c|}
\hline \multirow{2}{*}{ model PT2 } & \multicolumn{3}{|c|}{ Level Noise, $L_{\text {eq }}(\mathrm{dB}(\mathrm{A}))$} \\
\cline { 3 - 5 } & Driver & Co-driver & Crew \\
\hline$(\mathrm{km} / \mathrm{h})$ & Gear & \multicolumn{3}{|c|}{ Stable speed on asphalt } \\
\hline 60 & III & 85.8 & & 82.4 \\
\hline 60 & IV & 76 & & 74.7 \\
\hline 80 & IV & 79.2 & & 78.5 \\
\hline \multicolumn{5}{|c|}{ Stable speed at intersected slope heathland } \\
\hline 30 & III & 72 & & 68.5 \\
\hline 40 & III & 71.5 & & 69.7 \\
\hline \multicolumn{5}{|c|}{ Stable speed at flat macadam gravel } \\
\hline 20 & II & 74.3 & & 69.9 \\
\hline 30 & III & 76.1 & & 72.3 \\
\hline 40 & III & Acceleration, fourth gear on asphalt \\
\hline \multicolumn{5}{|c|}{} \\
\hline $40-80$ & IV & 76.7 & & 76 \\
\hline $40-90$ & IV & 80.1 & & 79 \\
\hline $50-100$ & IV & 82 & & 79.8 \\
\hline $50-100$ & V & 76.9 & & 75.8 \\
\hline \multicolumn{7}{|c|}{} \\
\hline
\end{tabular}

By analyzing all measured noise levels, it can be seen that the mean value of cabin noise during driving on asphalt was $75-76 \mathrm{~dB}(\mathrm{~A})$, at a stable speed of $60 \mathrm{~km} / \mathrm{h}$. By increasing the speed to $80 \mathrm{~km} / \mathrm{h}$, the value of the measured equivalent noise level reaches $80 \mathrm{~dB}(\mathrm{~A})$ - rounded to the next higher $\mathrm{dB}$. In the case of driving in third gear at a stable speed of $60 \mathrm{~km} / \mathrm{h}$, noise levels were $83-86 \mathrm{~dB}(\mathrm{~A})$. During acceleration tests (from 50 to $100 \mathrm{~km} / \mathrm{h}$ ), equivalent noise level reaches a value of $82 \mathrm{~dB}(\mathrm{~A})$ at the driver's seat (Tab. 6). It was also determined that the measured noise levels in the second seat row of the cabin were slightly lower than the ones from the first row, $79.8 \mathrm{~dB}(\mathrm{~A})$. However, it can be clearly seen from the above that the driver was exposed to noise above the threshold prescribed by the Directive 2003/10/ES - $80 \mathrm{~dB}(\mathrm{~A})$ - lower action value, and thus, the use of personal protective equipment is mandatory. Equivalent noise level in the vehicle cabin is also above the value defined by the Rulebook of measures and normatives for occupational protection from noise in workspaces $(80 \mathrm{~dB}(\mathrm{~A}))$. Taking into account the criteria for health risks, the obtained results indicate that driving of this off-road vehicle should be limited by speed, depending on the type of the track.

\subsection{Vibrations Test Results, "Model PT2"}

The results of the vibration test for "model PT2" are given in Tab. 7, for all three types of tracks. Based on the oscillatory comfort criteria, driving in the driver's seat, as well as the co-driver's seat and all others is considered uncomfortable in the case of intersected slope and macadam tracks. Driving on asphalt is at the limit of comfort for the driver and the passengers in the second row of seats.

Table 7 Results of measuring of forced oscillations of the off-road vehicle "model PT2" from the aspect of oscillatory comfort

\begin{tabular}{|c|c|c|c|c|}
\hline Track & $\begin{array}{c}\text { Measuring } \\
\text { point }\end{array}$ & $\begin{array}{l}\text { Speed } \\
(\mathrm{km} / \mathrm{h})\end{array}$ & $\begin{array}{l}\text { Equivalent triaxial acceleration } \\
\text { vs. comfort } \mathrm{a}_{\mathrm{v}}\left(\mathrm{m} / \mathrm{s}^{2}\right)\end{array}$ & Comfort rating \\
\hline \multirow{6}{*}{ Asphalt } & \multirow{2}{*}{ Driver } & 60 & 0.44 & Slightly uncomfortable \\
\hline & & 80 & 0.42 & Slightly uncomfortable \\
\hline & \multirow[b]{2}{*}{ Co-driver } & 60 & 0.53 & Mostly uncomfortable \\
\hline & & 80 & 0.68 & Mostly uncomfortable \\
\hline & \multirow{2}{*}{ Crew } & 60 & 0.48 & Slightly uncomfortable \\
\hline & & 80 & 0.51 & Mostly uncomfortable \\
\hline \multirow{6}{*}{$\begin{array}{c}\text { Slope } \\
\text { heathland }\end{array}$} & \multirow{2}{*}{ Driver } & 30 & 1.17 & Uncomfortable \\
\hline & & 40 & 1.36 & Very uncomfortable \\
\hline & \multirow[b]{2}{*}{ Co-driver } & 30 & 1.25 & Uncomfortable \\
\hline & & 40 & 1.38 & Very uncomfortable \\
\hline & \multirow{2}{*}{ Crew } & 30 & 1.23 & Uncomfortable \\
\hline & & 40 & 1.35 & Very uncomfortable \\
\hline \multirow{5}{*}{$\begin{array}{l}\text { Flat macadam } \\
\text { gravel }\end{array}$} & \multirow[b]{2}{*}{ Driver } & 30 & 1.81 & Very uncomfortable \\
\hline & & 40 & 1.87 & Very uncomfortable \\
\hline & \multirow{2}{*}{ Co-driver } & 30 & 1.86 & Very uncomfortable \\
\hline & & 40 & 1.89 & Very uncomfortable \\
\hline & Crew & 30 & 1.50 & Very uncomfortable \\
\hline
\end{tabular}

\subsection{Heat Related Comfort Efficiency of "Model PT2"}

Tests were performed in the hot chamber, whereas the efficiency of the air conditioner built into the "model PT2" was tested at temperature of $+40{ }^{\circ} \mathrm{C}$, in "cooling" mode, at user request. A total of 10 temperature sensors connected to the measuring device Fluke 2166 AK were placed inside the vehicle cabin. An integrated sensor MM0023, connected to a THERMAL COMFORT METER TYPE 1212 device, manufactured by Brüel \& Kjaer, was placed in the center of the cabin, behind the front seats. During the testing, measuring was performed using both instruments, and the obtained results are shown in Tabs. 8-9 [13]. Integrated sensor MM0023 was placed at a height of $0.6 \mathrm{~m}$ from the floor and at an angle of $30^{\circ}$ relative to the vertical axis. Temperature measuring sensors were placed at the heights of the head, chest and feet of the driver and the other crew members, in their seated positions.

During the time period od 15 minutes of working at an environmental temperature of $+40{ }^{\circ} \mathrm{C}$, the air conditioner built into "model PT2" fulfilled the comfort parameters PMV and PPD, as well as the vertical non-uniformity of temperature distribution $\Delta t$ (Tab. 9). 
Table 8 Temperatures measured by Fluke 2166 AK at environment temperature of $+40^{\circ} \mathrm{C}$

\begin{tabular}{|c|c|c|c|c|c|c|c|c|c|c|}
\hline & \multicolumn{10}{|c|}{ Temperatures $\left({ }^{\circ} \mathrm{C}\right)$} \\
\hline $\begin{array}{c}\text { Measuring } \\
\text { points }\end{array}$ & 1 & 2 & 3 & 4 & 5 & 6 & 7 & 8 & 9 & 10 \\
\hline Start (min) & 40 & 41 & 42 & 40 & 40 & 41 & 39 & 41 & 39 & 41 \\
\hline 5 & 32 & 31 & 30 & 32 & 31 & 30 & 31 & 34 & 18 & 42 \\
\hline 10 & 31 & 30 & 29 & 31 & 30 & 29 & 30 & 33 & 17 & 41 \\
\hline 15 & 30 & 29 & 29 & 30 & 29 & 29 & 30 & 32 & 17 & 41 \\
\hline 20 & 30 & 29 & 29 & 30 & 29 & 29 & 29 & 31 & 17 & 42 \\
\hline 25 & 30 & 29 & 28 & 30 & 29 & 29 & 29 & 31 & 17 & 42 \\
\hline 30 & 29 & 29 & 28 & 30 & 29 & 28 & 29 & 31 & 17 & 42 \\
\hline 35 & 29 & 29 & 28 & 30 & 28 & 28 & 29 & 31 & 17 & 43 \\
\hline 40 & 29 & 29 & 28 & 30 & 29 & 28 & 29 & 31 & 17 & 43 \\
\hline 45 & 29 & 29 & 28 & 30 & 28 & 29 & 29 & 31 & 17 & 43 \\
\hline 50 & 30 & 29 & 28 & 30 & 28 & 29 & 29 & 31 & 17 & 43 \\
\hline 55 & 30 & 29 & 29 & 30 & 29 & 29 & 29 & 31 & 17 & 42 \\
\hline 60 & 30 & 29 & 28 & 30 & 29 & 29 & 29 & 31 & 17 & 40 \\
\hline
\end{tabular}

Table 9 Heat related comfort measured by sensor MM0023 at $+40^{\circ} \mathrm{C}$

\begin{tabular}{|c|c|c|c|c|c|c|}
\hline Time (min) & Oper. temp. & Comp. temp. & Equivalent temp. & Temp. diff. $\Delta t$ & PMV & PPD \\
\hline 0 & 34.3 & 25 & 32.8 & 8.4 & -2.4 & 11 \\
\hline 5 & 35.1 & 25 & 27.1 & -0.24 & 0.75 & 18 \\
\hline 10 & 30.3 & 25 & 26.1 & -0.11 & 0.53 & 12 \\
\hline 15 & 29.7 & 25 & 25.1 & -0.5 & 0.28 & 8.2 \\
\hline 20 & 29.5 & 25 & 24.7 & 0 & 0.11 & 6.2 \\
\hline 25 & 29.4 & 25 & 24.6 & 0.2 & 0.13 & 6.5 \\
\hline 30 & 29 & 25 & 24 & 0.12 & -0.1 & 6.6 \\
\hline 35 & 28.8 & 25 & 23.8 & 0.5 & -0.11 & 6.1 \\
\hline 40 & 28.7 & 25 & 23.5 & 1 & -0.13 & 5.1 \\
\hline 45 & 28 & 25 & 23.6 & 0.6 & 0.2 & 6.2 \\
\hline 50 & 31 & 25 & 27 & 0.19 & 0.54 & 11 \\
\hline 55 & 30.8 & 25 & 27 & -2 & 0.54 & 11 \\
\hline 60 & 30.7 & 25 & 26.4 & -1.4 & 0.23 & 10 \\
\hline
\end{tabular}

\section{CONCLUSIONS}

Noise level in the cabins of both tested model of offroad cars were above prescribed and allowed values, taking into account the criteria for determining health risks. Based on the noise level results obtained, it was determined that driving of tested off-road vehicles should be limited in terms of speed and adapted to the type of track. It was concluded from the results obtained by noise level tests that "model PT1" has shown better results.

Based on the vibration comfort criteria, it was determined that driving in the driver's or co-driver's seat, as well as all other seats was very uncomfortable in the case of intersected slopes and macadam tracks for both tested models, and only in the case of "model PT2", driving on asphalt was comfortable for crew members in the second row of seats, at spped of $60 \mathrm{~km} / \mathrm{h}$. It can be concluded that the driving spped should be limited under difficult operating conditions, and also adapted to the type of track. Based on the results of vibration comfort measurement, "model PT2" had shown better results.

Heating efficiency measuring results for model "model PT1" have shown that the device used for achieving heat comfort during vehicle exploitation at lower temperatures of $-16{ }^{\circ} \mathrm{C}$ worked properly, and that it achieved the required heat comfort parameter during the defined time period of 45 minutes.

Testing of air conditioners in off-road vehicle "model PT2" determined that it fulfils the defined criteria at the environmental temperature of $+40{ }^{\circ} \mathrm{C}$. The air conditioner also fulfilled the comfort parameters PMV, PPD and the vertical non-uniformity of temperature distribution in the cabin $(\Delta t)$. Taking into account that the space in the cabin of "model PT1" was smaller, its heating and cooling efficiency, which is the most important comfort condition, was better than in the case of "model PT2".

The conclusion is that the advantage can be given to "model PT1", since, from the aspect of comfort, it has shown slightly better results as an off-road vehicle, compared to "model PT2", while noting that the manufacturer must improve the sound isolation and support and suspension systems in order to fully meet the standard requirements which are set to car manufacturer and the autommobile industry.

By comparing the results obtained by measuring of these two types of special off-road vehicles with the same results for the Land Rover Defender Soft Top and Land Rover Defender Hard Top [7], it can be concluded that during exploitation under off-road conditions, Zastava vehicles are almost equally as comfortable as those made by one of the most prestigeous off-road vehicle manufacturers, in terms of internal noise levels. Under operating conditions on asphalt, at the speed of $80 \mathrm{~km} / \mathrm{h}$, off-road vehicle PT1 had shown noise levels around $3 \mathrm{~dB}$ lower than that of PT2 cabin, but almost $3 \mathrm{~dB}$ above the noise level of the Land Rover Defender Hard Top, which represents a clear signal to the manufacturer that they need to devote more attention to soundproofing of the cabin, especially in models with an extended cabin - PT2.

Vibration measuring results for the driver's seat indicated that model PT1 is in the same category as the Land Rover Defender Soft Top, but also that it is 
significantly less comfortable compared to Land Rover Defender Hard Top for all types of tracks. Off-road vehicle Zastava PT1 achieved the poorest results in this segment.

Heat efficiency result for PT1 vehicles indicated that the average time needed to reach the temperature of $16{ }^{\circ} \mathrm{C}$ in the cabin was 35 minutes, while ensuring that the nonuniformity of temperature distribution is $\Delta t \leq 10{ }^{\circ} \mathrm{C}$ during this time interval. Similar measuring results have been obtained during the testing of Land Rover Defender vehicles as well [16].

Last, but not least, one can conclude that strict requirements about comfort parameters may be satisfied only if certain level of technological develpoment has been achieved, i.e. if a factory accepts them as a driving force for production improvement.

\section{REFERENCES}

[1] Stanković, M. (2017). Zavodi "Crvena Zastava": Yugoslav Self- Management Socialism and Challenges for the Automobile Industry. Etnoantropološki problemi, 12(3), 857-882. https://doi.org/10.21301/eap.v12i3.9

[2] Mićović, A., Popović, V., Mićović, D., \& Jovanović, S. (2013). Testing the characteristics of free and forced oscillations on FAP 2228 off-road vehicle. Journal off Applied Engineering Science, 114, 185-190.

[3] Lindov, O. (2008). Road Traffic Safety-Faculty of Traffic and Communications, University of Sarajevo, 157-159.

[4] Dai Y., Zhu X., \& Chen L. S. (2016). A MechanicalHydraulic Virtual Prototype Co-Simulation Model for a Seabed Remotely Operated Vehicle. International Journal of Simulation Modelling, 15(3), 532-541. https://doi.org/10.2507/IJSIMM15(3)C011

[5] ISO 5128:1980. Acoustic, Measurement of Noise Inside Motor Vehicles.

[6] Mićović, A., Popović, V., \& Jovanović, S. (2012). Acoustic testing inside cabin and passenger space of off-road vehicle land rover defender 110 soft top. Proceeding of Papers $23^{\text {th }}$ National conference \& $4^{\text {th }}$ International conference - Noise and vibration, $233-235$.

[7] Mićović, A., Popović, V., \& Sedmak, A. (2014). Potential for improvement of comfort parameters in off-road vehicles of Serbian Armed Forces. Technical Gazette, 21(5), 10091016.

[8] Pravilnik o merama i normativima zaštite na radu od buke u radnim prostorijama. Službeni list SFRJ, br. 21/92.

[9] Demić, M. \& Diligenski, Đ. (2012). A contribution to research of degradation of characteristic of vibration parameters of vibration aspect of vehicle comfort. Journal of Applied Engeneering Science (Istraživanja $i$ projektovanja za privredu), 4(10), 185-190.

[10] Demić, M., Diligenski, Đ., \& Milanović, M. (2013). A contribution to research of the influence of degradation of vehicle vibration parameters on thermal load of stock absorbers. Journal of Applied Engeneering Science (Istraživanja i projektovanja za privredu), 11(4), 23-30.

[11] ISO 2631-1:1997. Mechanical vibration and shock evaluation of human exposure to whole-body vibration Part 1: General requirements, 2014.

[12] Directive 2002/44/EC of the European parliament and of the Council of 25 June 2002 on the minimum health and safety requirements regarding the exposure of workers to the risks arising from physical agents (vibration) (sixteenth individual Directive within the meaning of Article 16(1) of Directive 89/391/EEC), 2002.

[13] ISO 8041:2005. Human response to vibration - Measuring instrumentation, 2013.
[14] ISO 7730:2005 International Standard - Ergonomics of the thermal environment - analytical determination and interpretation of thermal comfort using calculation of the PMV and PPD indicates and local thermal comfort criteria. International Standard Organization, Geneva 2005.

[15] Lenzuni, P., Freda, D., Del Gaudio, M. (2009). Classification of Thermal Environments for Comfort Assessment. Annals of Occupational Hygiene, 53(4), 325332. https://doi.org/10.1093/annhyg/mep012.

[16] Mićović, A. M. (2015). Integration and Evaluation of Influence of Comfort and Safety Parameters on SpecialPurpose Vehicles, PhD dissertation, Faculty of Mechanical Engineering, University of Belgrade.

\section{Contact information}

Milan STANKOVIĆ, MSc

$\mathrm{PhD}$ candidate, University of Belgrade

Studentski trg 1

11000 Belgrade, Serbia

E-mail: logistikamilan@gmail.com

\section{Aleksandar MIĆOVIĆ, PhD \\ Technical Test Centre \\ Vojvode Stepe 445 \\ 11000 Belgrade, Serbia \\ E-mail: amicovic1@gmail.com}

Aleksandar SEDMAK, Professor PhD

University of Belgrade

Faculty of Mechanical Engineering

Kraljice Marije 16

11020 Belgrade 35, Serbia

E-mail: aleksandarsedmak@yahoo.com

Vladimir POPOVIĆ, Professor PhD

University of Belgrade

Faculty of Mechanical Engineering

Kraljice Marije 16

11020 Belgrade 35, Serbia

E-mail: vladimir.popovic@mpn.gov.rs 